\title{
Tool rotational speed impact on temperature variations, mechanical properties and microstructure of friction stir welding of dissimilar high-strength aluminium alloys
}

\author{
Olatunji P. Abolusoro ${ }^{1}$ - Esther T. Akinlabi² · Satish V. Kailas ${ }^{3}$
}

Received: 9 August 2019 / Accepted: 26 February 2020 / Published online: 17 March 2020

(c) The Brazilian Society of Mechanical Sciences and Engineering 2020

\begin{abstract}
Temperature variations during friction stir welding result from the heat generated by the frictional action of a rotating tool on the workpiece. This temperature distribution affects the mechanical behaviour and ultimately the quality of welds produced. The study of the correlations between process parameter, temperature, mechanical properties and microstructure has become imperative in order to promote welds devoid of defects and possessing sound mechanical properties and to establish a temperature feedback control for effective components designs for industrial applications. This work studied the impact of tool rotational speed on temperature profile, mechanical behaviour and microstructure of friction stir welding of dissimilar aluminium alloy 6101-T6 and 7075-T651. Processing parameters of three different rotational speeds with values $1250 \mathrm{rpm}$, $1550 \mathrm{rpm}$ and $1850 \mathrm{rpm}$ and a constant travel speed of $50 \mathrm{~mm} / \mathrm{min}$ were employed. The temperature profile was measured with one end of thermocouple wires embedded in the plates and the other end connected to a data capturing software device. The temperature profile indicates that the temperature rises with time and is higher at the retreating sides than at the advancing side of the weld. The tensile test results show that the ultimate tensile strength decreases as the temperature increases. Microstructural observations of weld zone revealed non-uniformity in material flow. However, more material penetration into each other occurred more at $1550 \mathrm{rpm}$.
\end{abstract}

Keywords Aluminium alloys · Friction stir welding $\cdot$ Mechanical properties $\cdot$ Temperature

\section{Introduction}

Friction stir welding (FSW) is a welding technique that has gained wide use in the welding of low-temperature alloys especially aluminium alloys. The welding process involves the use of a rotating tool on a workpiece leading to the generation of heat which plasticized and stirred the workpiece joint together in a completely solid-state welding. There are various parameters that determine the quality of the weld.

Technical Editor: Lincoln Cardoso Brandao.

Olatunji P. Abolusoro

abolusoroolatunji@yahoo.com

1 Department of Mechanical Engineering Science, University of Johannesburg, Johannesburg, South Africa

2 Department of Mechanical Engineering, Covenant University, Ota, Nigeria

3 Department of Mechanical Engineering, Indian Institute of Science, Bangalore, India
Such parameters include tilt angle, axial force, travel speed, plunge depth, rotational speed, tool pin geometry, temperature distribution, etc. These factors affect the heat generated and the plasticization and flow of the materials during friction stir welding and consequently affect the mechanical properties and quality of the weld [1-4]. Studies have indicated a direct link between weld temperature and mechanical behaviour of a friction stir weld joint. Microstructural evolution, defects, corrosion, wear and mechanical properties are all direct consequences of temperature distributions during welding and are often determined by processing parameters employed during the welding [5-10]. Microstructural changes during FSW has been reported by various researchers [11-16]. Precipitate dissolution and coarsening including precipitate-free formation regions have been identified in the weld zone [17, 18]. The formation of these microstructural changes has also been linked to processing parameters such as feed rate and tool rotational speed $[11,19,20]$. Tool rotational speed has been established as one of the important process variables in FSW. This particular variable affects 
the strain rate behaviour of the recrystallization process [21]. Researchers have reported that there is an optimal tool rotational speed range within which quality welds can be achieved [22]. Lombard et al. [23] employed eleven combinations of tool feed rate and rotational speed for systemic optimization. Their report showed that the maximum tensile strength of $313 \mathrm{MPa}$ at a rotational speed of $200 \mathrm{rpm}$ was achieved. In a related study, Aruna et al. [24] studied three tool rotational parameters impact on the mechanical strength of FSW of 5083 aluminium alloy. They concluded that the rotating speed of $1200 \mathrm{rpm}$ yielded the maximum UTS. Izabela et al. [25] also studied the effects of tool rotational speed on the FSW of 7075-T651 and 5083-H111 aluminium alloys. They reported that better material mixing was obtained at higher rotational speed but the mechanical properties reduce as the rotational speed goes up. However, Min-Su-Han et al. [26] in their report revealed that excessively high temperature from high welding speed could result in defects and poor mechanical properties. Umasanka and Vijay [27] studied the correlation between temperature, rotational speed and mechanical strength of FSW of 6101-T6 and 6351-T6 alloys. The results indicate that there is a corresponding increase in temperature as the rotational speed increases. The mechanical impact strength of the weld varies with the duration of impact and pressure. Prasad et al. [28] also studied the effect of the rotational speed of $100 \mathrm{rpm}$ and $1000 \mathrm{rpm}$ on microstructural changes and creep properties of low-temperature FSW of P91 steel. The welding temperature was measured at the tooltip, and the result revealed that temperature control is essential for a reduction in microstructural degradation during welding. Silva et al. [29] investigated the temperature variation during FSW of 6082 aluminium alloy with $20 \mathrm{~mm}$ thickness. The temperatures were measured at three different positions around the tool. The results show that the highest temperature of $607^{\circ} \mathrm{C}$ was obtained from the thermocouple placed at the transition from the shoulder to the pin, while the lowest occurred at the pin's tip. Kandasamy et al. [30] also investigated the temperature generated both on the tool and the workpiece during FSW of 7075 alloys. The maximum temperature obtained was compared with simulated results and was found to be in close agreement. Temperature measurements with high accuracy during FSW are often difficult to carry out through validation of the experiment. This is as a result of severe plastic deformation that occurs and could damage the thermocouple at the hottest region which is the interface between the rotating tool and the workpiece where the temperature is expected to be measured [6, 31]. Many researchers have utilized several approaches to measure or predict temperature during FSW. Some of these approaches include the use of thermal cameras and thermocouple embedded in tool [32-34]. Others include infrared thermometers, ultrasound, neutron-based methods $[9,31]$ and thermocouples embedded in the workpiece [27, 35,
36]. The most commonly employed among these methods in literature is the use of thermocouples embedded in the workpiece at close proximity to the rotating pin area [37]. However, this approach also has the disadvantage of having the thermocouple destroyed during the passage of the rotating tool [9]. Thermocouple placed at the surface of the plates to be welded would give a higher temperature than those placed behind the plates particularly when the materials for backing plates possess high thermal conductivity. These make different positions of thermocouple found in various studies $[6,38]$. In this work, the thermocouple used was embedded into the workpiece at a proximity to the heat affected zone. It is pertinent to point out that tool rotational speed on workpiece generates the needed heat for FSW and cause temperature changes. Its influence often differs in FSW of dissimilar alloys. Although considerable amount of studies has been done on effects of tool rotational speed on the tensile strength of some friction stir welded aluminium alloys, however, majority of the works focused only on the relationship between the tool rotational speed and the tensile strength of the weld. Only very few attempts have been made to establish the relationship between the tool rotational speed, the generated temperature during the welding, the microstructures and material flow pattern and the mechanical properties of the friction stir welded aluminium alloys. The correlations between these factors are very significant in welding process control for industrial applications and are yet to be reported on friction stir dissimilar welding of 6101T6 and 7075-T651 aluminium alloys. This study, therefore, focuses on how the tool rotational speed causes variations in temperatures and how these variations affect the microstructure, material flow and mechanical properties of dissimilar FSW of 7075-T651 and 6101-T6 aluminium alloys. These aluminium alloys have been selected in view of their high strength-to-weight ratio, corrosion resistance, high thermal and electrical conductivity which have made them strategic and important materials in aerospace and automobile applications.

\section{Experimental procedures}

\subsection{Sample's chemical composition and properties}

The elemental composition and the mechanical properties obtained from the tested samples of the alloys are shown in Tables 1 and 2.

\subsection{Process parameters}

The fixed travel speed and the different rotational speed of the tool employed for the experiment are given in Table 3 . These parameters were chosen based on trial runs carried out 
Table 1 Chemical composition of the welded aluminium alloys $(\% \mathrm{wt})$

\begin{tabular}{llllllllll}
\hline Alloy & $\mathrm{Si}$ & $\mathrm{Cu}$ & $\mathrm{Fe}$ & $\mathrm{Mn}$ & $\mathrm{Mg}$ & $\mathrm{Ti}$ & $\mathrm{Cr}$ & $\mathrm{Zn}$ & $\mathrm{Al}$ \\
\hline 6101-T6 & 0.53 & 0.01 & 0.14 & 0.002 & 0.600 & 0.008 & 0.001 & 0.003 & Others \\
7075-T651 & 0.40 & 1.70 & 0.50 & 0.300 & 2.40 & 0.20 & 0.22 & 5.50 & Others \\
\hline
\end{tabular}

Table 2 Mechanical properties of the welded alloy

\begin{tabular}{lllll}
\hline Alloy & $\begin{array}{l}\text { Tensile } \\
\text { strength } \\
(\mathrm{MPa})\end{array}$ & $\begin{array}{l}\text { Ultimate tensile } \\
\text { strength }(\mathrm{MPa})\end{array}$ & $\begin{array}{l}\text { Elon- } \\
\text { gation } \\
(\%)\end{array}$ & $\begin{array}{l}\text { Thermal } \\
\text { conductivity } \\
\left(\mathrm{W} / \mathrm{m}^{* \circ} \mathrm{C}\right)\end{array}$ \\
\hline 6101-T6 & 172 & 180 & 21 & 167 \\
$7075-\mathrm{T} 651$ & 462 & 575 & 18 & 130 \\
\hline
\end{tabular}

Table 3 Rotational speeds and travel speeds

\begin{tabular}{ll}
\hline $\begin{array}{l}\text { Rotational speed } \\
(\mathrm{rpm})\end{array}$ & $\begin{array}{l}\text { Travel } \\
\text { speed (mm/ } \\
\text { min) }\end{array}$ \\
\hline 1250 & 50 \\
1550 & 50 \\
1850 & 50 \\
\hline
\end{tabular}

prior to this experiment. Five different tool rotational speeds (950 rpm, $1250 \mathrm{rpm}, 1550 \mathrm{rpm}, 1850 \mathrm{rpm}$ and $2150 \mathrm{rpm}$ ) at two different travel speeds of $50 \mathrm{~mm} / \mathrm{min}$ and $80 \mathrm{~mm} / \mathrm{min}$ were carefully selected around the optimized values from the literature [39] for the trial runs. The welds from the rotational speeds of $950 \mathrm{rpm}$ and $2150 \mathrm{rpm}$ at both travel speeds of $50 \mathrm{~mm} / \mathrm{min}$ and $80 \mathrm{~mm} / \mathrm{min}$ were found to develop root defects, an indication of too low heat input and too high heat input, respectively. The tool rotational speeds of $1250 \mathrm{rpm}$, $1550 \mathrm{rpm}$ and $1850 \mathrm{rpm}$ at the travel speed of $50 \mathrm{~mm} / \mathrm{min}$ gave defect-free welds. These three parameters were therefore selected to carry out this study. The details of the procedure followed are given in Sect. 2.3.

\subsection{Experimental procedures}

The two aluminium alloys to be welded were properly cleaned to remove dirt and oxide layers that might have been formed on the surface. The tool of pin length $5.65 \mathrm{~mm}$ with a root diameter of $7.3 \mathrm{~mm}$ and pin mouth diameter of $5.5 \mathrm{~mm}$ and a shoulder diameter of $22 \mathrm{~mm}$ as shown in Fig. 1a, b was used for the experiment. The experiment was carried out with a $100 \mathrm{kN}$ numerical welding machine designed and manufactured by IISc, Bangalore, and ETA Technology Ltd, Bangalore, India. The experimental setup and the welding arrangement for the study are shown in Fig. 2. The two alloys were clamped in butt configuration with the 6101T6 placed on the advancing side (AS), while the 7075-T651 was placed on the retreating side (RS). The advancing side (a)

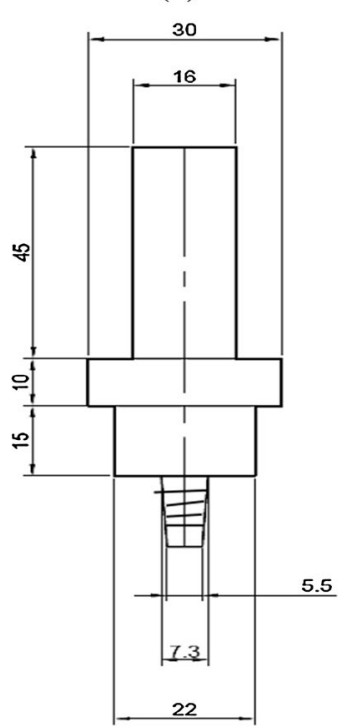

(b)

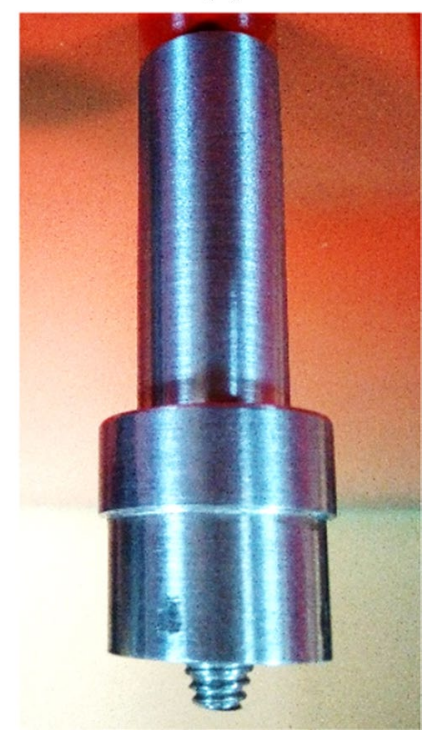

Fig. 1 a Schematic diagram of the tool. b Photograph of the tool

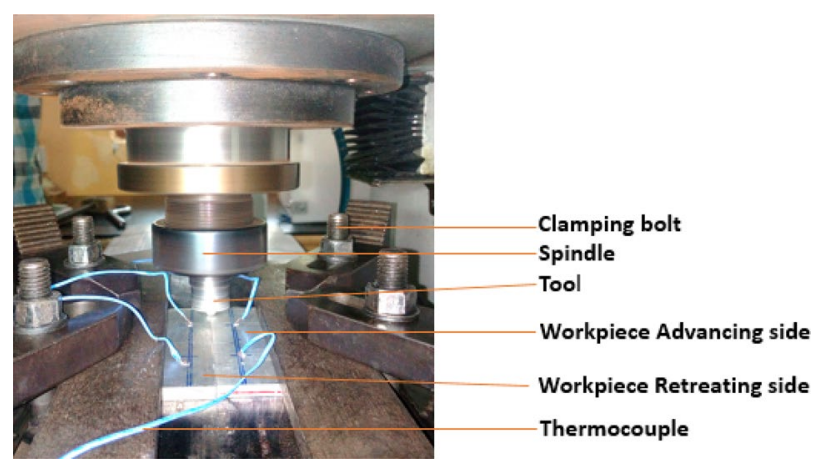

Fig. 2 Experimental setup and welding arrangements

is that side of the weld in which the rotating tool movement and the traversing direction is the same. Here, the solid materials are transformed into semi-solid or plasticized and flow around the tool pin rotating at the interface of the two materials to be joined. The retreating side, on the other hand, is the side of the weld where the direction of tool rotation is opposite to the traversing direction. Here, the plasticized materials from the advancing side retreated and get cooled. The four ends of the thermocouple wires used were embedded at four different points in the plates, two on each side of the plate at about $2 \mathrm{~mm}$ away from the weld boundaries as shown in Fig. 3. The other four ends were connected to 
Fig. 3 Thermocouple arrangements

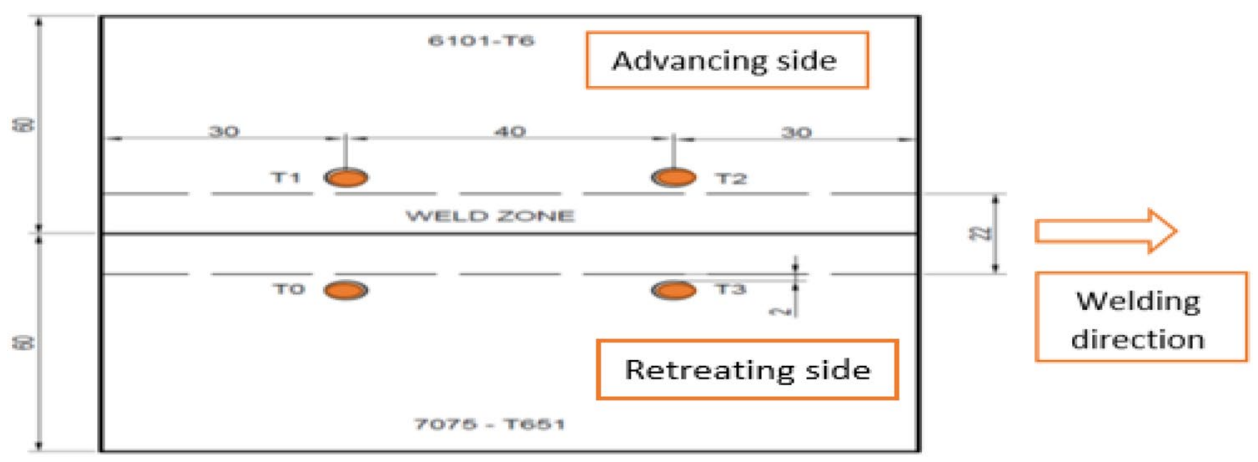

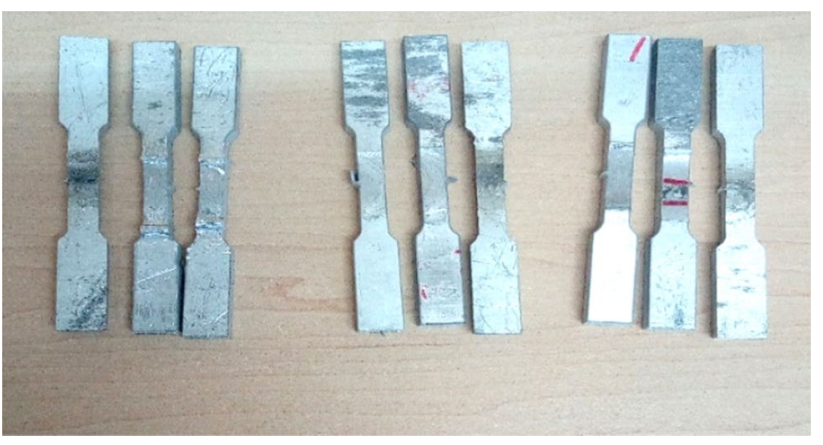

Fig. 4 Prepared tensile samples

Labview evaluation software for temperature data capturing and analysis. The friction stir welding was performed at three different parameters shown in Table 3. The specimens for tensile testing were prepared in accordance with ASTM E8 as shown in Fig. 4. Three tensile specimens were tested for each processing parameter, and the average ultimate tensile strength values for each were taken for evaluation.

\section{Results and discussion}

\subsection{Weld appearance}

Careful observations of the welds after the welding as shown in Fig. 5 revealed that the welds are externally free from defects although, very little flashes could be noticed in the welds.

\subsection{Temperature profile}

The profile of the highest temperatures obtained during the welding for each of the parameters as shown in Fig. 6 indicate that the temperature rises with time and attained a maximum at the middle of the welding. Each welding parameter exhibits different temperature profiles at the retreating and the advancing side of the weld. This is as a result of different amount of heat generated during the welding which

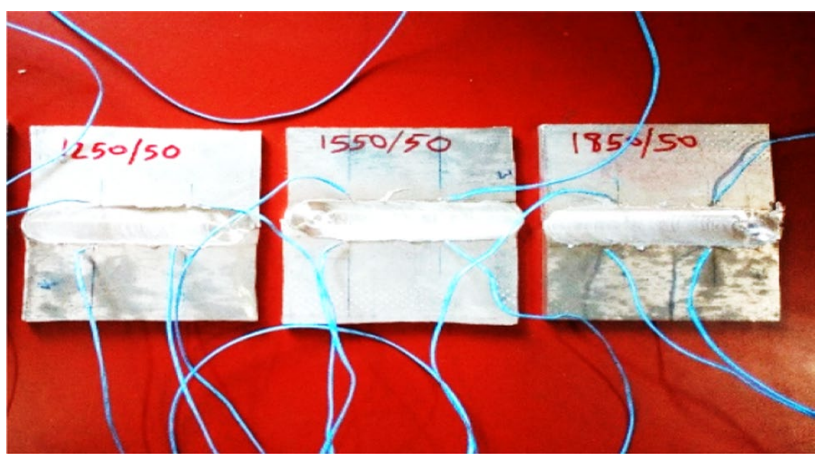

Fig. 5 Welded samples

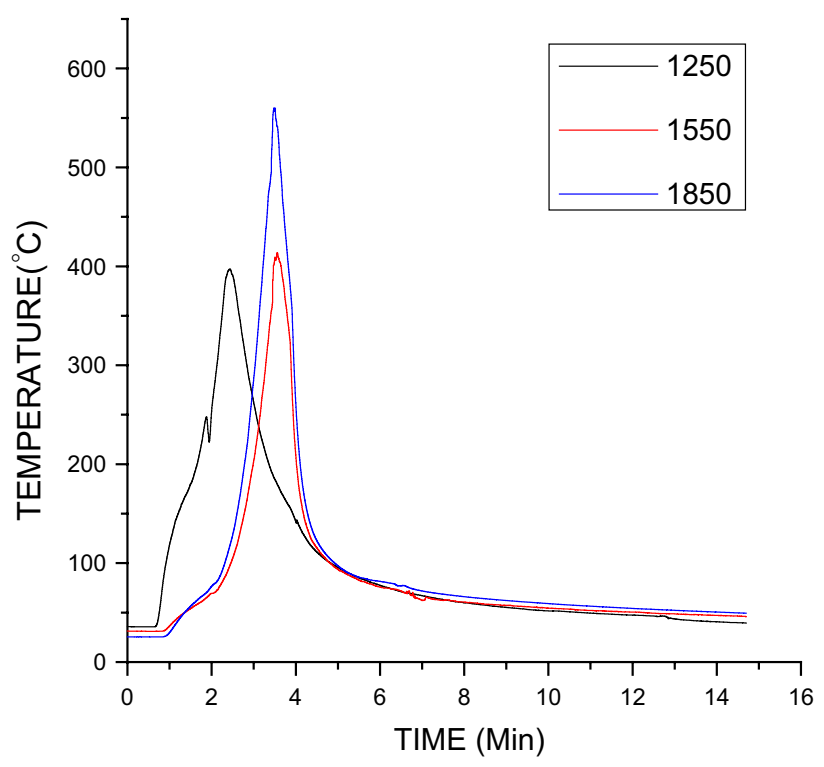

Fig. 6 Highest temperature profile of the three different welding parameters

emanates from different processing parameters employed. At the $1250 \mathrm{rpm}$, the highest temperature at the advancing side is $366^{\circ} \mathrm{C}$ which is lower than $397^{\circ} \mathrm{C}$ obtained at the retreating side. This is shown in Fig. 7. However, at $1550 \mathrm{rpm}$, as shown in Fig. 8, the advancing side highest temperature is 


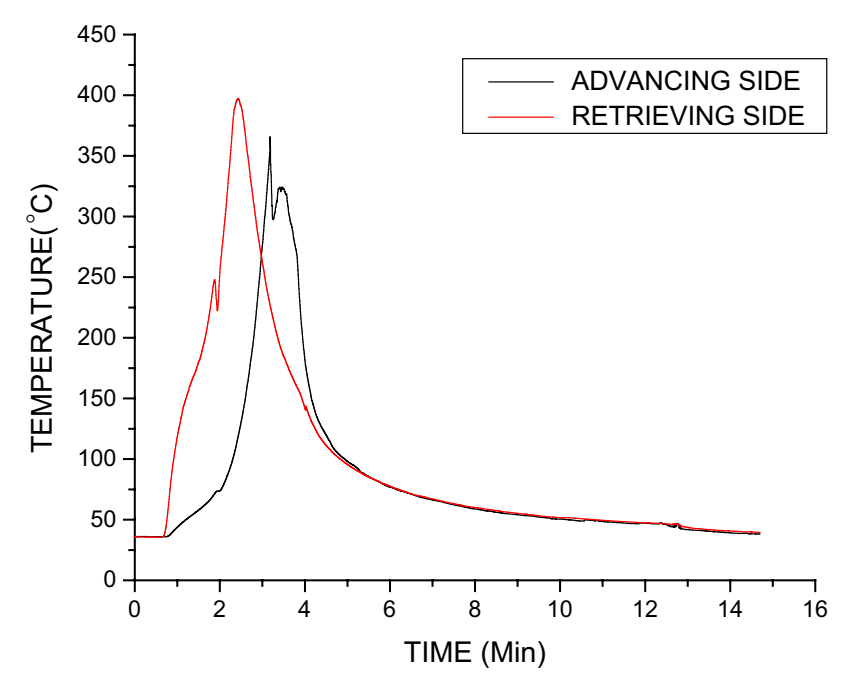

Fig. 7 Temperature profile at $1250 \mathrm{rpm}$ for advancing and retreating side

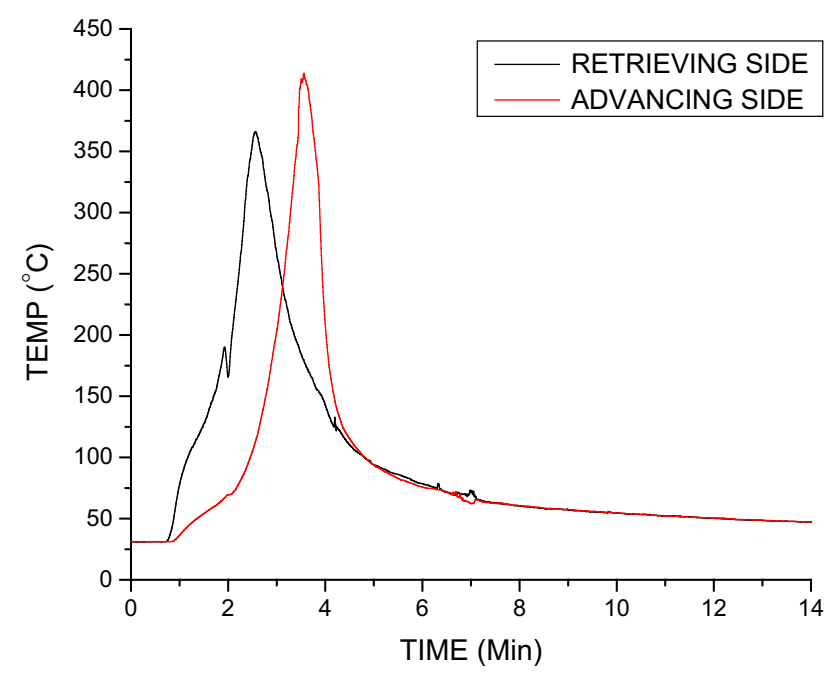

Fig. 8 Temperature profile at $1550 \mathrm{rpm}$ for advancing and retreating side

$414{ }^{\circ} \mathrm{C}$ which is higher than $366^{\circ} \mathrm{C}$ obtained at the retreating side. This could be due to absorption of part of the heat generated by the latent heat of the alloy at the retreating side of the weld and the heat loss rate on the advancing side seems to be much lower than the rate of heat absorbed at the retreating side. However, as the rotational speed increases to $1850 \mathrm{rpm}$, the highest temperature obtained at the 6101-T6 side and 7075-T651 sides is $471{ }^{\circ} \mathrm{C}$ and $560{ }^{\circ} \mathrm{C}$, respectively. This is shown in Fig. 9. This means that temperature variations at the $1250 \mathrm{rpm}$ and $1850 \mathrm{rpm}$ exhibit similarity in behaviour as the highest temperature at the 7075-T651 on the retreating side is greater than that of 6101-T6 on the advancing side for both parameters. The variations in these

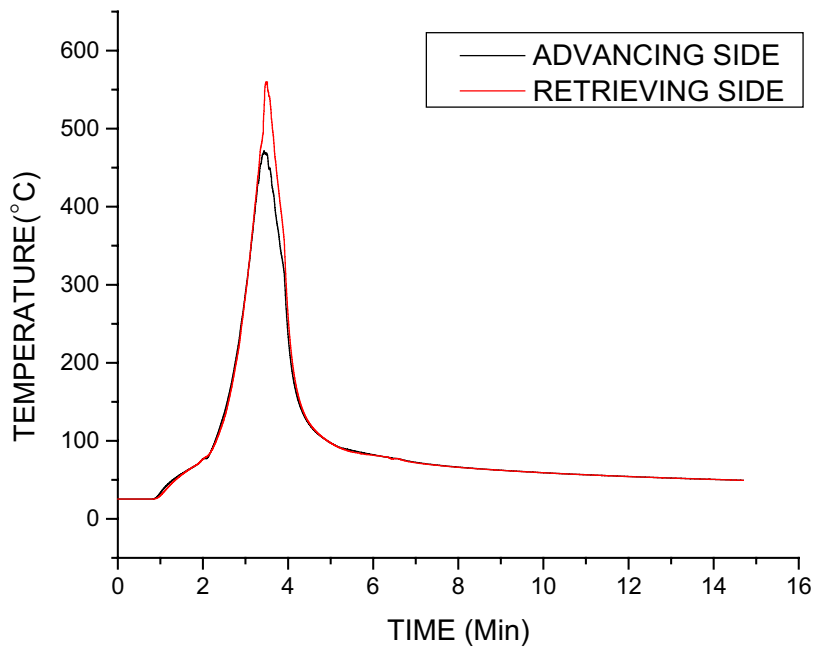

Fig. 9 Temperature profile at $1850 \mathrm{rpm}$ for advancing and retreating side

temperature profiles at the advancing and retreating sides can be attributed to inhomogeneous heat distributions and transferred as a result of differences in the thermal conductivity of both alloys. The thermal conductivity of 6101-T6 is higher than that of 7075-T651; hence, heat transfer occurred faster in 6101-T6 than in 7075-T651. This also implies that the rate of heat losses in the 6101-T6 is higher than that of 7075-T651 and consequently leads to lower temperature obtained at the advancing side of the welds.

\subsection{Effects of rotational speed on the temperature}

The heat generated during friction stir welding results from the frictional effects of the rotating tool on the workpiece. The temperature measured indicates that the highest temperature of about $550{ }^{\circ} \mathrm{C}$ was obtained at a tool rotational speed of $1850 \mathrm{rpm}$. The lowest recorded occurred at a rotational speed of $1250 \mathrm{rpm}$. The temperature considerably increases across the weld samples as the rotating tool speed increases as shown in Fig. 10. This is due to greater frictional effects of the rotating tool on the workpiece as the rotational speed increases leading to a higher amount of heat generation and consequently raising the weld temperature.

\subsection{Effects of rotational speed on tensile behaviour}

The tool's rotation on the workpiece considerably affects the tensile behaviour of the welds. As the rotational speed of the tool goes higher, there is a corresponding reduction in the tensile strength of the welds. This is shown in Fig. 11. The highest ultimate tensile strength of $143 \mathrm{MPa}$ was obtained at the lowest rotational speed of the tool. This can be ascribed to more heat input into the system when the rotational speed increases. The 


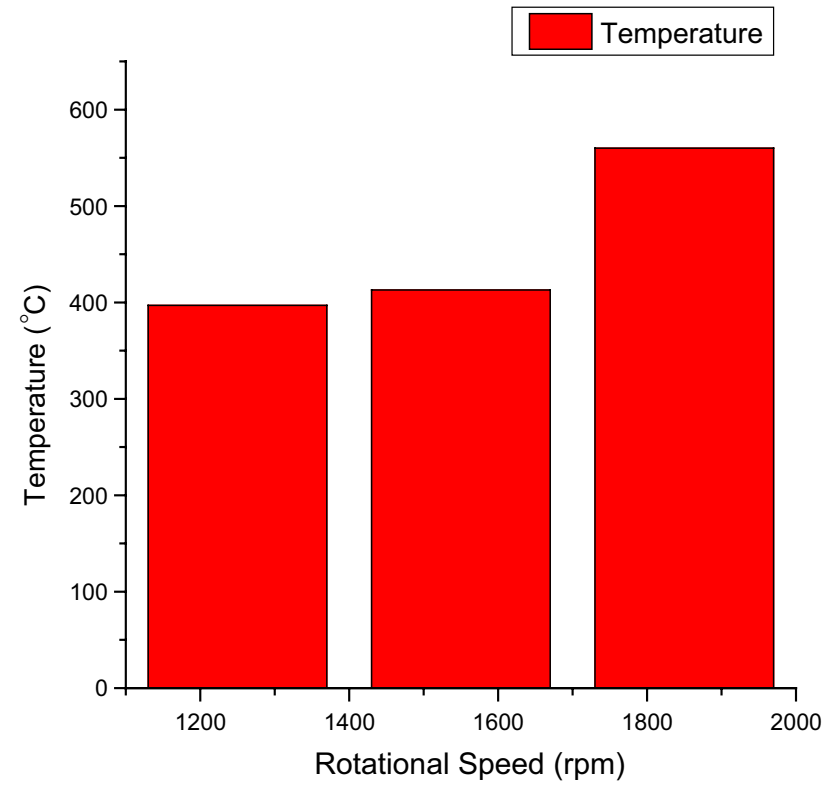

Fig. 10 Effect of rotational speed on temperature

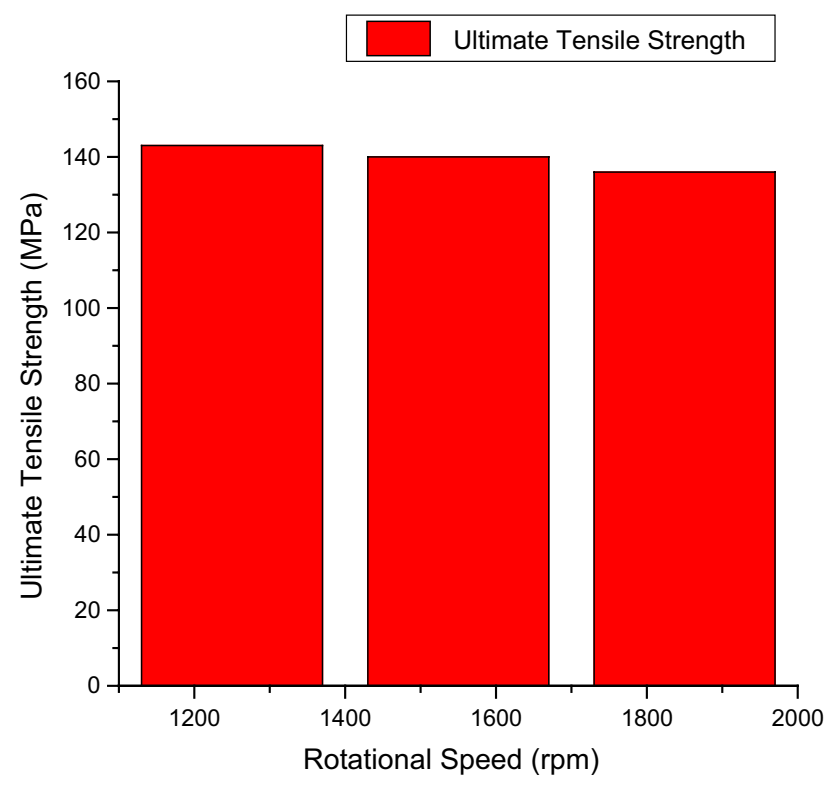

Fig. 11 Effect of rotational speed on tensile strength

increase in heat input causes microstructural changes in the weld region. The strengthening precipitates become coarsened leading to lower grain bonding which consequently reduced the tensile strength of the welds.

\subsection{Temperature distribution effects on tensile behaviour}

The heat produced during friction stir welding emanates from the friction between the tools rotating on the stationary workpiece. The produced heat affects plasticization, transfer and mixing of materials at the stir zone. These further determine the microstructural development at the joint interface and consequently affect the mechanical behaviour of the joints. The tensile test results obtained as shown in Fig. 12 indicate that the highest ultimate tensile strength of $143 \mathrm{MPa}$ occurred at the lowest weld temperature. As the temperature increases due to the increase in tool rotational speed, there is a decrease in the ultimate tensile strength across the welds. This decrease could be as a result of coarsening or dissolution of precipitates at the weld zone due to higher heat generation which results in weak bonding at the weld zone. The little differences observed in the ultimate tensile strength across the welds at different temperature changes indicate that the amount of changes in heat generated in the welds due to tool rotational speed changes is not sufficient enough to cause significant coarsening and precipitates dissolution at the weld zone, hence, the little changes in the ultimate tensile strength of the weld.

\subsection{Tensile test analysis}

The average tensile test results for the three welded samples along with both base metals are shown in Fig. 13. The results revealed that the ultimate tensile strengths of all the welds were lesser than those of the parent metals. The percentage elongations for the welds were also

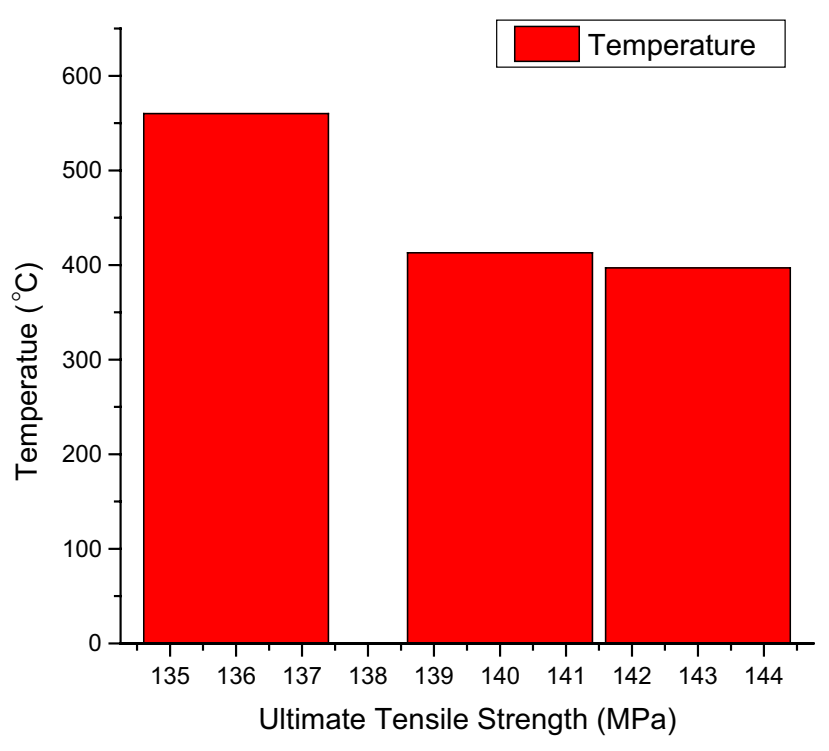

Fig. 12 Effect of temperature on tensile strength 


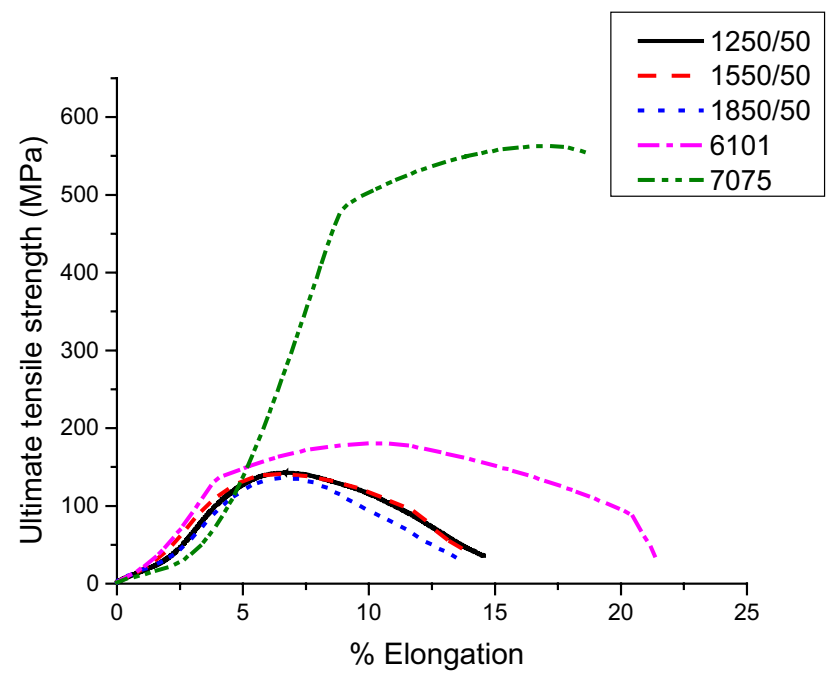

Fig. 13 Graph of ultimate tensile strength against percentage elongation

Table 4 Weld efficiency at different rotational speeds

\begin{tabular}{lll}
\hline $\begin{array}{l}\text { Process parameter }(\mathrm{rpm} / \\
\mathrm{mm} / \mathrm{min})\end{array}$ & $\begin{array}{l}\text { Ultimate tensile strength } \\
(\mathrm{MPa})\end{array}$ & $\begin{array}{l}\text { Efficiency } \\
\text { of welds } \\
\text { in \% }\end{array}$ \\
\hline $1250 / 50$ & 143 & 79 \\
$1550 / 50$ & 140 & 77 \\
$1850 / 50$ & 136 & 75 \\
\hline
\end{tabular}

found to be lower than those of the base metals. The joint efficiencies of the welds calculated as the ratio of the ultimate tensile strength of the welds to that of 6101-T6 base metals expressed in percentage are shown in Table 4 . The efficiency of the weld reduces as the temperature increases due to the increase in rotational speed.

\subsection{Fracture analysis}

The mode of fracture of the tensile specimens observed revealed that the fracture took place at the heat affected zone (HAZ) close to the 6101-T6 side as shown in Fig. 14a-d. This can be attributed to its lower mechanical strength compared to 7075-T651. Also, the microstructural reorientations of the grains at that section lead to the formation of coarse precipitates with the resultant reduction in mechanical properties as a result of heat. The non-failure of the alloys at the weld zone is an indication of proper material mixing and bonding of the dissimilar metals for all the parameters employed. Considerable necking before failure was observed in all the tested specimen of the welds as shown in Fig. 14 $\mathrm{b}-\mathrm{d}$. This implies that the material undergoes extensive plastic deformation before the fracture occurred. This behaviour is synonymous with ductile materials like aluminium alloys. The fractographs of the tensile specimens are shown in Fig. 15a-e. All the fractographs of the three process parameters utilized as shown in Fig. 15a-c significantly show similarities in the fracture pattern. This is due to the failure of all the samples at the heat affected zone of the 6101-T6 side of the welds. The fractographs equally revealed that plastic deformation and necking occurred before the material fractured. This is evident in the fracture morphology of the tested specimens which are generally characterized by fibrous features, an indication that the crack propagation occurred slowly. Equiaxed dimples with voids are noticeable (Fig. 15a-d) which is a typical behavioural pattern of ductile materials. The dimples are structures emanated from the nucleation, growth and coalescence of voids. These voids are formed as a result of the inhomogeneous rate of deformation
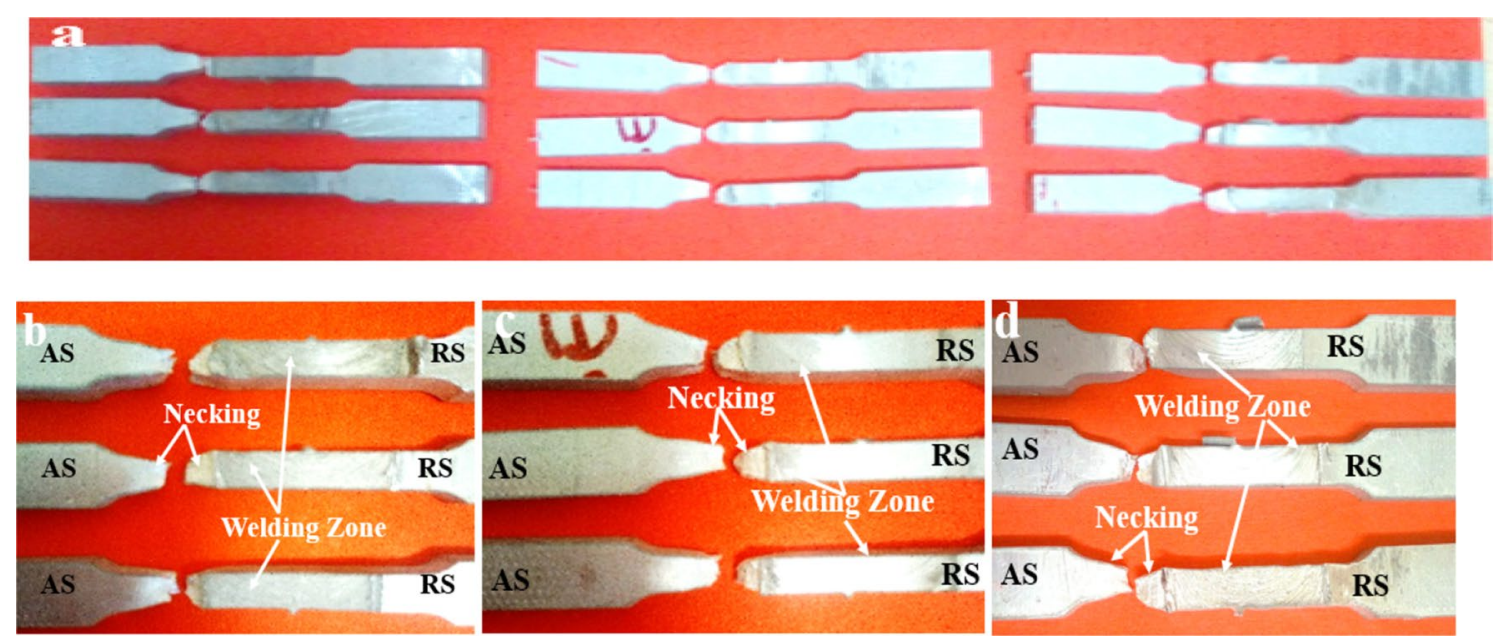

Fig. 14 Fractured specimen. a All the tested specimen. b $1250 \mathrm{rpm}$. c $1550 \mathrm{rpm}$. d $1850 \mathrm{rpm}$ 

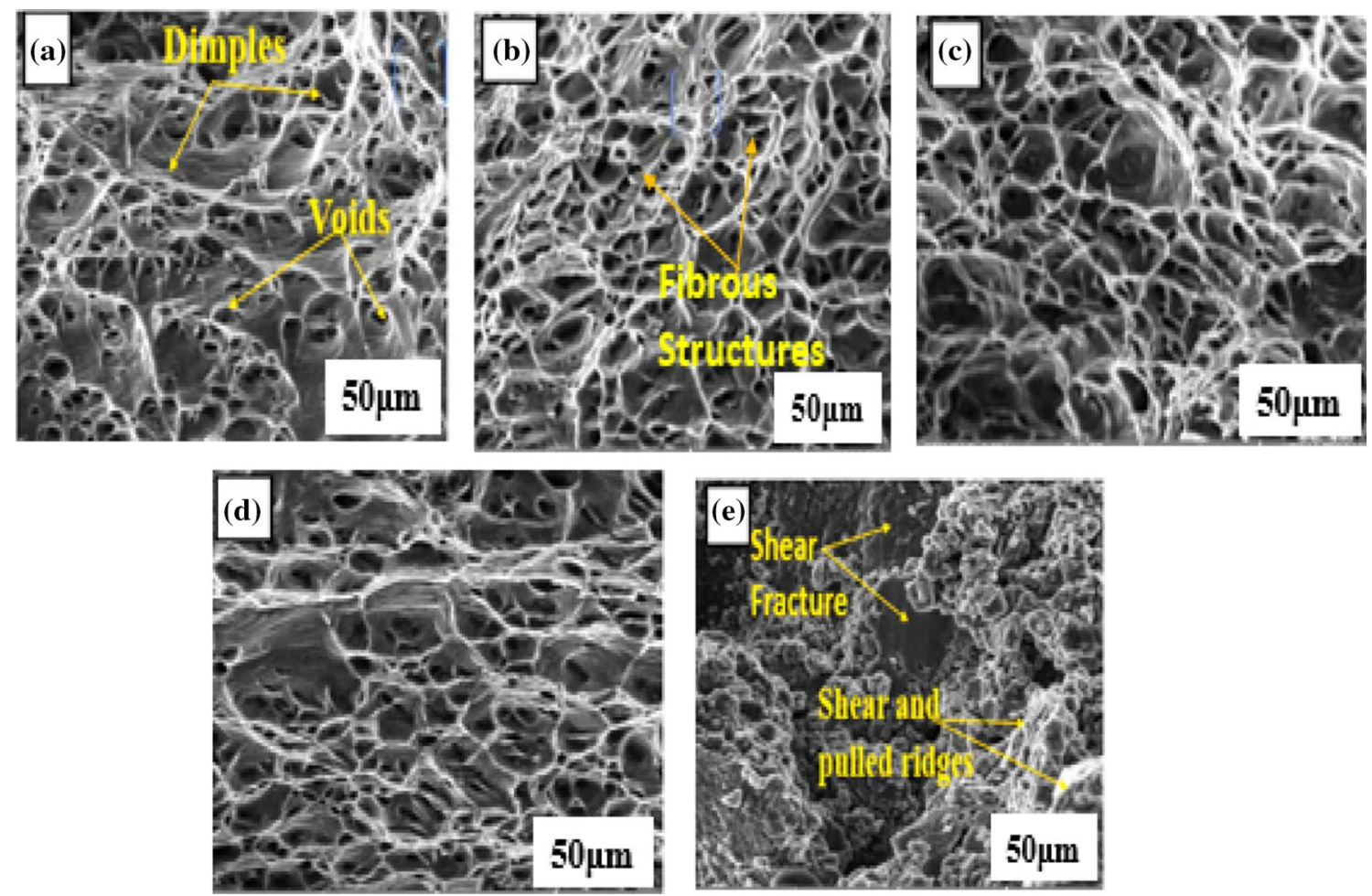

Fig. 15 SEM fractographs of the tensile tests fractured surfaces at $1.00 \mathrm{k} \times$ for a $1250 \mathrm{rpm}$ at $50 \mathrm{~mm} / \mathrm{min}$. b $1550 \mathrm{rpm}$ at $50 \mathrm{~mm} / \mathrm{min}$. c $1850 \mathrm{rpm}$ at $50 \mathrm{~mm} / \mathrm{min}$. d Base material 6101-T6. e Base material 7075-T651

in the material under the applied load. The growth and coalescence of these voids controlled the fractured behaviour. When these voids grow to critical sizes relative to the spacing in-between them, a local plastic instability developed leading to the formation of macroscopic flaws which resulted in the fracture. The 6101-T6 base material has the highest percentage of elongation. The ultimate tensile strength was much higher than those of the welded samples; however, it is far below that of the 7075-T651, and the fracture pattern observed in the 6101-T6 alloy (Fig. 15d) is similar to those obtained for the welded samples. This is due to the failure of the welded samples at the 6101-T6 side. 7075-T651 exhibits the highest ultimate tensile strength although the percentage elongation was a little lower than the other base metal of 6101-T6. The fracture pattern of the 7075-T651 did not demonstrate appreciable necking before failure. This indicates lower ductility compared to the other base metal. The cracking features as shown in Fig. 15e indicate a transgranular mode of cracking accompanied by shear and pulled fractures.

\subsection{Hardness}

The microhardness was profiled across the welding direction at $1-\mathrm{mm}$ interval. The hardness values varied across the three zones of the weld, i.e. heat affected zone (HAZ), nugget zone (NZ) and thermo-mechanically affected zone (TMAZ) and exhibited similar transformation pattern across the three parameters used in this study as shown in Fig. 16. At the 7075-T651 side which is the retreating side on the left of the NZ, the microhardness increases from base metal towards the HAZ and became maximum at the TMAZ just before the NZ. This is due to grain refinement as a result of heat experienced at the zone. At the NZ, the microhardness values droped drastically. This can be attributed to inhomogeneity in the composition of the welding zone brought about by material mixing during the

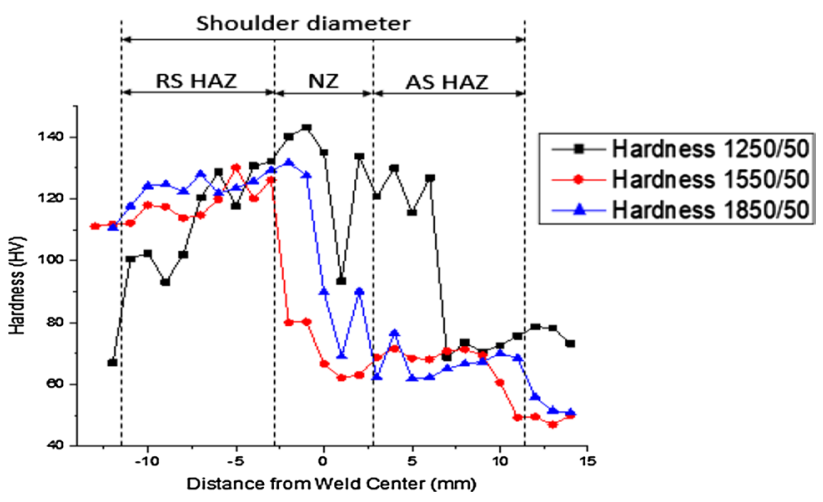

Fig. 16 Hardness profile of the three rotational speeds 
FSW and coarsening of precipitates at this region which reduces hardness. At the HAZ of the advancing side which is the 6101-T6 on the right side of the NZ in Fig. 16, the hardness values further droped as expected. This is as a result of dissolutions of strengthening precipitates of the alloy in this zone. The highest hardness values at NZ and both sides of the HAZ were obtained at the rotational speed of $1250 \mathrm{rpm}$. This is due to better grain refinement at these zones as the tool generates a significant amount of heat needed for grain cohesion than the other two parameters with higher temperatures. Further analysis of the hardness variations across the three zones of the welds is shown in Fig. 17. The average hardness values evaluated from the welding zones of all the parameters demonstrate similarity in behaviour. At the NZ, the highest average hardness value of $122.62 \mathrm{HV}$ was obtained at the rotational speed of $1250 \mathrm{rpm}$. As the speed increases to $1550 \mathrm{rpm}$, there is a drastic drop in the hardness value, but it moved up again as the tool rotational speed goes up to $1850 \mathrm{rpm}$. At the HAZ of the AS, the same pattern with the NZ was exhibited. The average hardness value of $81.88 \mathrm{HV}$ was the highest and also occurred at $1250 \mathrm{rpm}$ but droped a little at $1550 \mathrm{rpm}$ and then moved slightly higher at $1850 \mathrm{rpm}$. At the HAZ of the retreating side, the highest average microhardness value of 119.2 was obtained and occurred also at the same $1250 \mathrm{rpm}$. A decrease in the value was equally noticed as the tool rotational speed increases to $1550 \mathrm{rpm}$ and moved up again as the speed increases to $1850 \mathrm{rpm}$. The drop in average hardness at $1550 \mathrm{rpm}$ across the three zones could probably be as a result of coarsening of the strengthening precipitates due to more heat input from

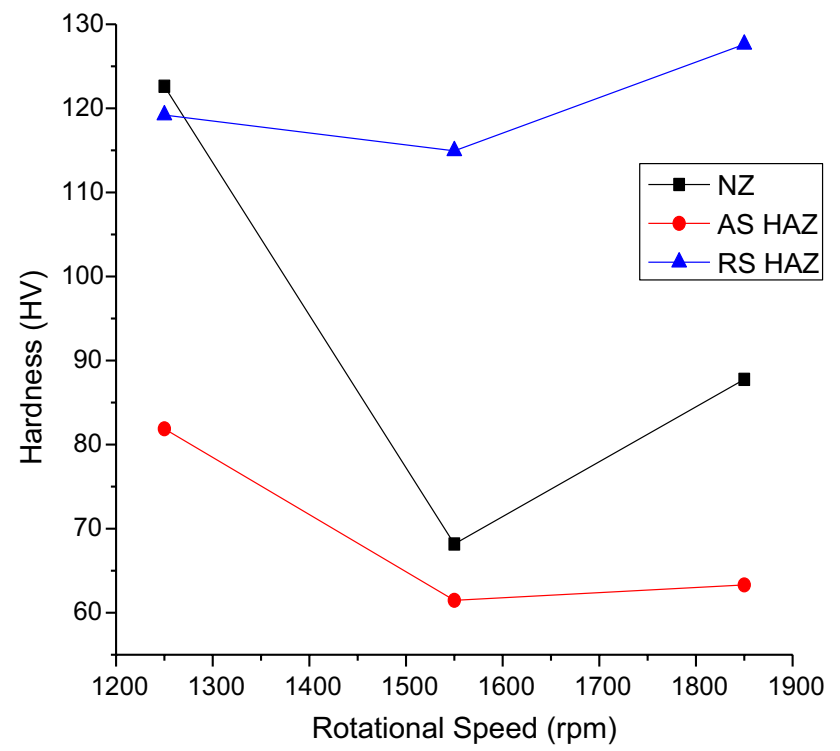

Fig. 17 Average hardness values at NZ, AS HAZ and RS HAZ of the three rotational speeds the higher rotational speed. Although a further increase in the rotational speed to $1850 \mathrm{rpm}$ caused a little rise in the average hardness across the zones, it might be as a result of improvement in the material movement at that rotational speed.

\subsection{Microstructure}

The mixing and dilution of the two dissimilar alloys at the joint interface during the welding occurred as a result of the rotational effect of the tool. Although the weld dilution could not be ascertained in this study, however, the mixing pattern and material flow at the different rotational speed employed have been revealed through the macrostructure and microstructural observations of the weld zones. The macrostructures as shown in the macrographs in Figs. 18a, 19a and 20a revealed that there is sufficient heat for plasticization of the joint interface at all the three tool rotational speeds. Transformation of materials across the depth joint is not uniform as a result of varying contact area own to the tapered pin used. However, more material interaction occurred at the $1250 \mathrm{rpm}$ rotational speed than in the $1550 \mathrm{rpm}$ and $1850 \mathrm{rpm}$.

The microstructures vary across the length and breadth of the weld zone and generally formed three types of regions which agree to the findings of some researchers on dissimilar FSW of aluminium alloys [40-44]. The regions can be classified into mixed flow, mechanically mixed and unmixed region. The unmixed region is found at the uppermost part of the joint close to the tool shoulder region (Figs. 18c, 19c, 20c). The heat emanated from the tool rotating mechanism on the workpiece impacts on the microstructures of the region which becomes refined in grain structures leading to the occurrence of dynamic recrystallization during the welding. The mechanically mixed region contains microstructure of both 6101-T6 and 7075-T651 aluminium alloys (Figs. 18d, 19d, 20d). The Weck's reagent etchant revealed 7075-T651 as a lighter colour and 6101-T6 as a darker colour. Full penetration of the aluminium alloys into each other was not accomplished in all the welds. However, substantial materials were swept into each other at the tool rotational speeds of $1250 \mathrm{rpm}$ and $1550 \mathrm{rpm}$. Onion ring structures of material flow were visible in $1550 \mathrm{rpm}$ and $1850 \mathrm{rpm}$. This is shown in Figs. $19 \mathrm{~b}$ and 20b. The mixed region like the mechanically mixed region also contains the microstructures of both alloys. Here, the alloys flow into each other in alternate layers in lamellae structural pattern as shown in Figs. 18e, $19 \mathrm{e}$ and $20 \mathrm{e}$. The SEM microstructure of the weld zones for all the welds is given in Fig. 21a-c. Interfacial and alternate layered flow structure occurred in all the zones. 
Fig. 18 Optical images of material flow pattern and microstructures of weld nugget zone at $100 \times$ for $1250 \mathrm{rpm}$. a Macrograph of the joint, $\mathbf{b}$ material flow pattern, $\mathbf{c}$ unmixed, $\mathbf{d}$ mechanically mixed, e mixed regions
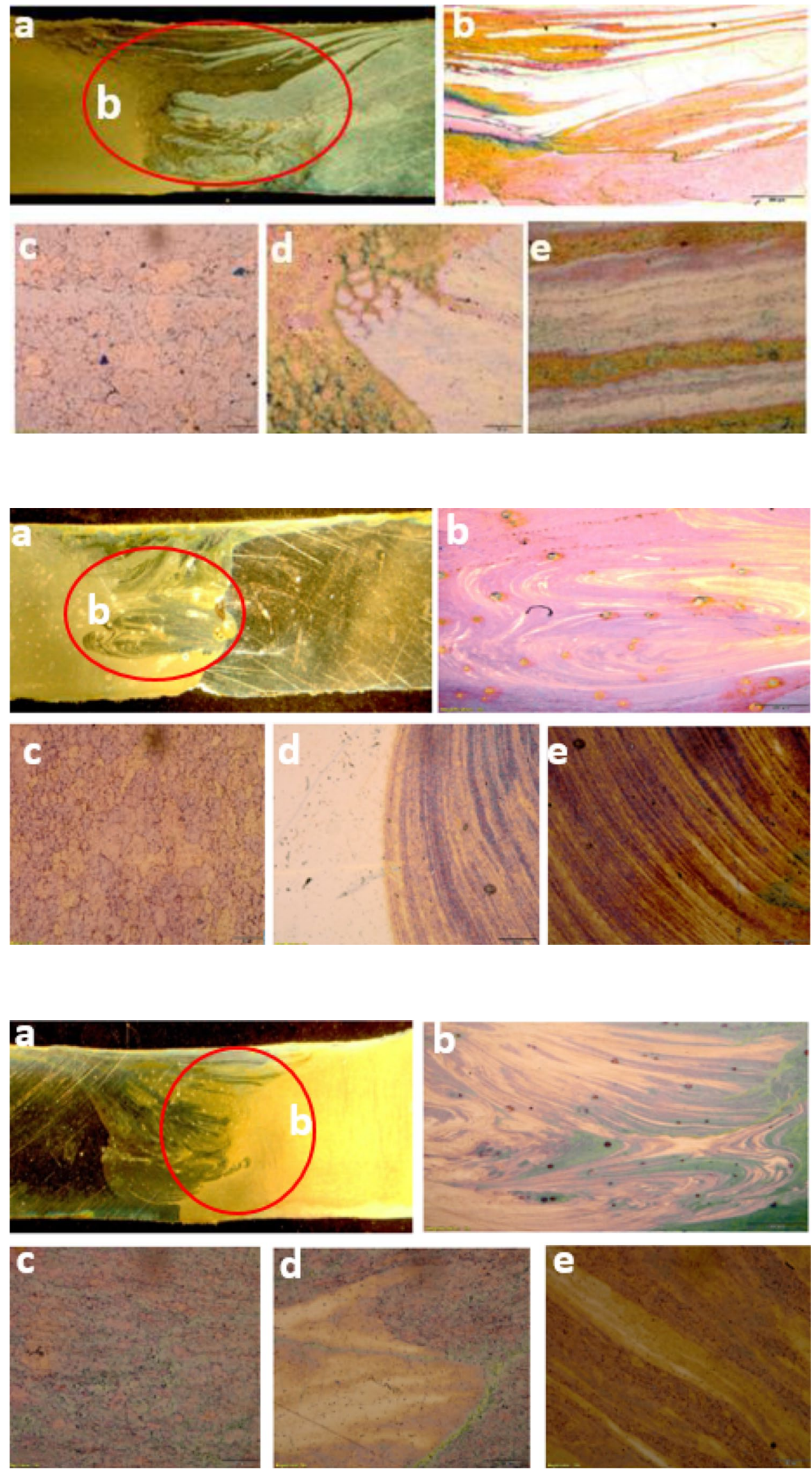

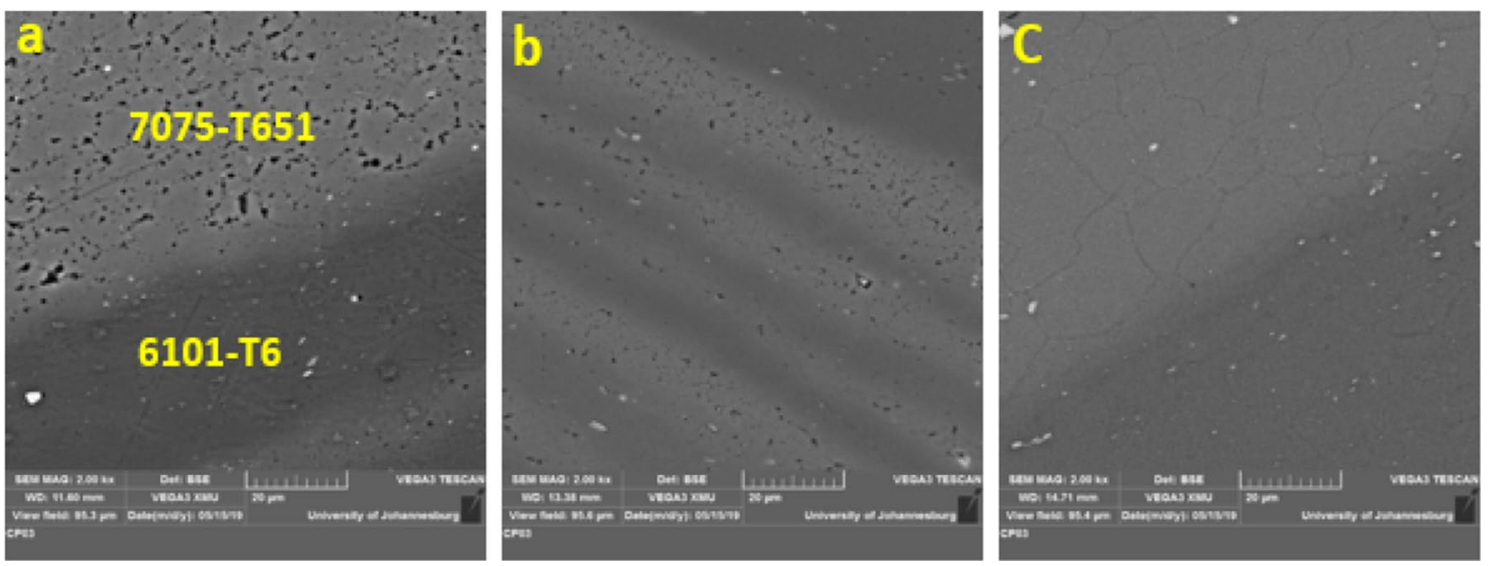

Fig. 21 SEM microstructures of mixed region at $20 \mu \mathrm{m}$. a $1250 \mathrm{rpm}, \mathbf{b} 1550 \mathrm{rpm}$, c $1850 \mathrm{rpm}$

\section{Conclusion}

The experimental study above has further established the relationship between temperature distributions in friction stir welding and the resulting mechanical properties and microstructures. Conclusions from these relationships can be drawn as follows:

1. The temperature is directly proportional to the rotational speed of the tool. An increase in the speed of rotation of the tool leads to an increase in temperature.

2. The lower temperature at a considerable range during the friction stir welding favours improvement in tensile strength of the joints.

3. Higher temperature beyond the optimum value during the friction stir welding decreases the mechanical properties.

4. The little differences observed in the ultimate tensile strength across the welds indicate that $300 \mathrm{rpm}$ tool rotational speed differences may not be sufficient to cause significant changes in the ultimate tensile strength of the weld.

5. The observed temperature profile of the welding revealed that temperature increases with time and attained its peak in the middle of the welding.

6. Material distributions in the welding zone are not even. The volume of material swept into one another was more in $1250 \mathrm{rpm}$. However, the highest penetration of the alloy into one another occurred at the $1550 \mathrm{rpm}$ rotational speed.

\section{References}

1. Sidhu MS, Chatha SS (2012) Friction stir welding-process and its variables: a review. Int J Emerg Eng Technol Adv Eng 2(12):275

2. Bagheri Hariri M, Gholami Shiri S, Yaghoubinezhad Y, Mohammadi Rahvard M (2013) The optimum combination of tool rotation rate and travelling speed for obtaining the preferable corrosion behaviour and mechanical properties of friction stir welded AA5052 aluminium alloy. Mater Des 50:620-634

3. Mishra RS, Ma ZY (2005) Friction stir welding and processing. Mater Sci Eng R. https://doi.org/10.1016/j.mser.2005.07.001

4. Padhy GK, Wu CS, Gao S (2018) Friction stir based welding and processing technologies - processes, parameters, microstructures and applications: a review. J Mater Sci Technol 34:1-38

5. Abolusoro PO, Akinlabi ET (2019) Wear and corrosion behaviour of friction stir welded aluminium alloys-an overview. Int J Mech Prod Eng Res Dev 9:967-982

6. Silva ACF, De Backer J, Bolmsjö G (2017) Temperature measurements during friction stir welding. Int J Adv Manuf Technol 88:2899-2908

7. Khandkar MZH, Khan JA, Reynolds AP (2003) Prediction of temperature distribution and thermal history during friction stir welding: input torque based model. Sci Technol Weld Join 8:165-174

8. Tang J, Shen Y (2016) Numerical simulation and experimental investigation of friction stir lap welding between aluminium alloys AA2024 and AA7075. J Alloys Compd. https://doi.org/10.1016/j. jallcom.2016.01.138

9. Fehrenbacher A, Duffie NA, Ferrier NJ, Pfefferkorn FE, Zinn MR (2014) Effects of tool-workpiece interface temperature on weld quality and quality improvements through temperature control in friction stir welding. Int J Adv Manuf Technol 71:165-179

10. Bie J, Liu Y-L, Zhang Z (2008) Effect of processing parameters on temperature distributions in friction stir welding. Suxing Gongcheng Xuebao J Plast Eng 15(3):212-217

11. Hassan KAA, Prangnell PB, Norman AF, Prince DA, Williams SW (2003) Effect of welding parameters on nugget zone microstructure 
and properties in high strength aluminium alloy friction stir welds. Sci Technol Weld Join. https://doi.org/10.1179/136217103225005 480

12. Rhodes CG, Mahoney MW, Bingel WH, Spurling RA, Bampton CC (1997) Effects of friction stir welding on microstructure of 7075 aluminium. Scr Mater. https://doi.org/10.1016/S1359-6462(96)00344 $-2$

13. Bisadi H, Tavakoli A, Tour Sangsaraki M, Tour Sangsaraki K (2013) The influences of rotational and welding speeds on microstructures and mechanical properties of friction stir welded Al5083 and commercially pure copper sheets lap joints. Mater Des. https://doi. org/10.1016/j.matdes.2012.06.029

14. Sato YS, Kokawa H, Enomoto M, Jogan S (1999) Microstructural evolution of 6063 aluminium during friction-stir welding. Metall Mater Trans A Phys Metall Mater Sci. https://doi.org/10.1007/s1166 1-999-0251-1

15. Rodrigues DM, Loureiro A, Leitao C, Leal RM, Chaparro BM, Vilaça P (2009) Influence of friction stir welding parameters on the microstructural and mechanical properties of AA 6016-T4 thin welds. Mater Des. https://doi.org/10.1016/j.matdes.2008.09.016

16. Abolusoro PO, Akinlabi ET (2020) In-process cooling in friction stir welding of aluminium alloys - an overview. In: Awang $\mathrm{M}$ et al (eds) Advances in material sciences and engineering. Lecture notes in mechanical engineering. Springer, Singapore, pp 435-444. https ://doi.org/10.1007/978-981-13-8297-0_45

17. Jata KV, Sankaran KK, Ruschau JJ (2000) Friction-stir welding effects on microstructure and fatigue of aluminium alloy 7050T7451. Metall Mater Trans A Phys Metall Mater Sci. https://doi. org/10.1007/s11661-000-0136-9

18. Mahoney MW, Rhodes CG, Flintoff JG, Spurling RA, Bingel WH (1998) Properties of friction-stir-welded 7075 T651 aluminum. Metall Mater Trans A 29(7):1955-1964

19. Lotfi AH, Nourouzi S (2014) Effect of welding parameters on microstructure, thermal, and mechanical properties of friction stir welded joints of Aa7075-T6 aluminium alloy. Metall Mater Trans A Phys Metall Mater Sci. https://doi.org/10.1007/s11661-014-2235-z

20. Guo JF, Chen HC, Sun CN, Bi G, Sun Z, Wei J (2014) Friction stir welding of dissimilar materials between AA6061 and AA7075 $\mathrm{Al}$ alloys effects of process parameters. Mater Des. https://doi. org/10.1016/j.matdes.2013.10.082

21. Aydin H, Bayram A, Esme U, Kazancoglu Y, Guven O (2010) Application of grey relation analysis (Gra) and Taguchi method for the parametric optimization of friction stir welding (FSW) process. Appl Grey Relat 44:205-211

22. Rajakumar S, Balasubramanian V (2012) Establishing relationships between mechanical properties of aluminium alloys and optimised friction stir welding process parameters. Mater Des 40:17-35

23. Lombard H, Hattingh DG, Steuwer A, James MN (2008) Optimising FSW process parameters to minimise defects and maximise fatigue life in 5083-H321 aluminium alloy. Eng Fract Mech 75:341-354

24. Prabha KA, Putha PK, Prasad BS (2018) Effect of tool rotational speed on mechanical properties of aluminium alloy 5083 weldments in friction stir welding. Mater Today Proc 5(24):18535-18543

25. Kalemba-Rec I, Kopyściański M, Miara D, Krasnowski K (2018) Effect of process parameters on mechanical properties of friction stir welded dissimilar 7075-T651 and 5083-H111 aluminium alloys. Int J Adv Manuf Technol. https://doi.org/10.1007/s00170-018-2147-y

26. Han MS, Lee SJ, Park JC, Ko SC, Woo Y Bin, Kim SJ (2009) Optimum condition by mechanical characteristic evaluation in friction stir welding for 5083-O Al alloy. Trans Nonferrous Met Soc China (Engl Ed). https://doi.org/10.1016/S1003-6326(10)60238-5

27. Das U, Toppo V (2018) Effect of tool rotational speed on temperature and impact strength of friction stir welded joint of two dissimilar aluminum alloys. Mater Today Proc 5:6170-6175

28. Kalevala PR, Akram J, Misra M, Ramachandran D, Gabbita JR (2016) Low-temperature friction stir welding of P91 steel. Def Technol 12:285-289
29. Silva-magalhães A, Backer J De, Martin J, Bolmsjö G (2019) In-situ temperature measurement in friction stir welding of thick section aluminium alloys. J Manuf Process Elsevier 39:12-17

30. Schmale J, Fehrenbacher A, Shrivastava A, Pfefferkorn FE (2016) Calibration of dynamic tool-workpiece interface temperature measurement during friction stir welding. Meas J Int Meas Confed 88:331-342

31. Feng Z, Hubbard CR, David SA, Brown DW, An K, Clausen B et al (2007) In situ neutron diffraction measurements of temperature and stresses during friction stir welding of 6061-T6 aluminium alloy. Sci Technol Weld Join 12:298-303

32. Hamilton C, Dymek S, Sommers A (2010) Characteristic temperature curves for aluminum alloys during friction stir welding. Weld $\mathrm{J}$ 89:189s-194s. https://doi.org/10.1016/j.ijmachtools.2008.02.001

33. Buffa G, Donati L, Fratini L, Tomesani L (2006) Solid-state bonding in extrusion and FSW: process mechanics and analogies. J Mater Process Technol 177:344-347

34. Covington JL, Robison W, Webb B (2005) Experimental characterization of tool heating during friction stir welding. ASM Proceedings of the International Conference: Trends in Welding Research, pp 179-184

35. Takayama Y, Akutsu Y, Choshiro N, Kato H, Watanabe H (2010) Temperature measurement during friction stir welding of dissimilar aluminum alloys, pp 1829-1834

36. Miles M, Karki U, Hovanski Y (2014) Temperature and material flow prediction in friction-stir spot welding of advanced highstrength steel. JOM 66:2130-2136

37. Upadhyay P, Reynolds AP (2010) Effects of thermal boundary conditions in friction stir welded AA7050-T7 sheets. Mater Sci Eng A 527:1537-1543

38. Fehrenbacher A, Smith CB, Duffie NA, Pfefferkorn FE, Ferrier NJ, Zinn MR (2013) Combined temperature and force control for robotic friction stir welding. J Manuf Sci Eng 136:021007. https:// doi.org/10.1115/1.4025912

39. Swaminathan G, Sathiyamurthy S (2018) Experimental study of mechanical and metallurgical properties of friction stir welded dissimilar aluminium alloys. Int J Mech Prod Eng Res Dev 8(1):1049-1058

40. Palanivel R, Koshy Mathews P, Murugan N, Dinaharan I (2012) Effect of tool rotational speed and pin profile on microstructure and tensile strength of dissimilar friction stir welded AA5083-H111 and AA6351-T6 aluminium alloys. Mater Des 40:7-16

41. Shigematsu I, Kwon YJ, Suzuki K, Imai T, Saito N (2003) Joining of 5083 and 6061 aluminium alloys by friction stir welding. J Mater Sci Lett. https://doi.org/10.1023/A:1022688908885

42. Ouyang JH, Kovacevic R (2002) Material flow and microstructure in the friction stir butt welds of the same and dissimilar aluminium alloys. J Mater Eng Perform 11:51-63

43. Abolusoro PO, Akinlabi ET (2019) Experimental investigations of tool pin geometry and process parameter influence on mechanical property of friction stir welded 6101-T6 and 7075-T651 aluminium alloys. In: International conference on engineering for sustainable world, 2019, p 1378

44. Abolusoro PO, Akinlabi ET (2020) Effects of processing parameters on mechanical, material flow and wear behaviour of friction stir welded 6101-T6 and 7075-T651 aluminium alloys. Manuf Rev 7:1

Publisher's Note Springer Nature remains neutral with regard to jurisdictional claims in published maps and institutional affiliations. 